ORIGINAL ARTICLE

\title{
Mechanisms of head injuries in elite football
}

\author{
T E Andersen, Á Árnason, L Engebretsen, R Bahr
}

Br J Sports Med 2004;38:690-696. doi: 10.1136/bjsm.2003.009357

\begin{abstract}
Objectives: The aim of this study was to describe, using video analysis, the mechanisms of head injuries and of incidents with a high risk of head injury in elite football.

Methods: Videotapes and injury information were collected prospectively for 313 of the 409 matches played in the Norwegian (2000 season) and Icelandic (1999 and 2000 season) professional leagues. Video recordings of incidents where a player appeared to be hit in the head and the match was consequently interrupted by the referee were analysed and cross referenced with reports of acute time loss injuries from the team medical staff.

Results: The video analysis revealed 192 incidents (18.8 per 1000 player hours). Of the 297 acute injuries reported, $17(6 \%)$ were head injuries, which corresponds to an incidence of 1.7 per 1000 player hours (concussion incidence 0.5 per 1000 player hours). The most common playing action was a heading duel with 112 cases (58\%). The body part that hit the injured player's head was the elbow/arm/hand in 79 cases $(41 \%)$, the head in 62 cases $(32 \%)$, and the foot in 25 cases (13\%). In 67 of the elbow/arm/hand impacts, the upper arm of the player causing the incident was at or above shoulder level, and the arm use was considered to be active in 61 incidents $(77 \%)$ and intentional in 16 incidents $(20 \%)$.

Conclusions: This study suggests that video analysis provides detailed information about the mechanisms for head injuries in football. The most frequent injury mechanism was elbow to head contact, followed by head to head contact in heading duels. In the majority of the elbow to head incidents, the elbow was used actively at or above shoulder level, and stricter rule enforcement or even changes in the laws of the game concerning elbow use should perhaps be considered, in order to reduce the risk of head injury.
\end{abstract}

See end of article for authors' affiliations Correspondence to: DrT E Andersen, Oslo Sports Trauma Research Center, Norwegian University of Sport and Physical Education, PO Box 4014, Ulleval Stadion, 0806 Oslo, Norway; thor.einar. andersen@nih.no

Accepted

2 December 2003

$F$ ootball is the only contact sport that exposes a large number of participants to purposeful use of the head for controlling and advancing the ball. ${ }^{1}$ Based on a series of cross sectional studies ${ }^{2-5}$ on active and older retired Norwegian football players, using neurological examinations, neuropsychological tests, computer tomography (CT) scans, and electroencephalography (EEG) examinations, Tysvær et al ${ }^{5}$ postulated in 1991 that heading the ball could lead to chronic brain injury such as that seen in boxers. ${ }^{6}$ Since then, several cross sectional studies have indicated that football can cause sustained measurable brain impairment, ${ }^{7-11}$ and this has caused significant concerns over the effects of repetitive heading in soccer. ${ }^{12}$ In response to this, protective headgear has been manufactured for football; however, no standards exist and it is still unclear whether these devices would protect players from blows to the head. Naunheim et $a l^{13}$ showed in a recent experimental study that headgear has little ability to reduce impact when heading, but they suggest that headbands may play a role in attenuating the impact for more forceful blows at the highest speeds.

However, it should be noted that in the absence of longitudinal cohort studies it is not possible to decide whether repetitive heading is the cause of the cognitive deficiencies observed among football players. In a recent review, Kirkendall et al ${ }^{1}$ state that to date it appears that heading is not likely to be a significant factor, but that the reported deficits are more likely to be the result of accidental head impacts that occur during the course of the matches.

Head injuries account for 4-22\% of all football injuries. ${ }^{14-19}$ However, this figure incorporates all types of head injuries, including facial fractures, lacerations, and eye injuries. The rate of brain injuries is difficult to assess because of the problem of defining and grading concussions. ${ }^{1}$ Nevertheless, it appears that the higher the level of play and the more competitive the league, the higher the incidence of concussions. ${ }^{18-21}$
There is limited information on the mechanisms of head injury in football. ${ }^{1}$ Studies based on player reports or reports by team medical personnel show that injuries mainly result from contact with other players. ${ }^{22-28}$ Boden et al ${ }^{19}$ prospectively studied collegiate female and male players and found that about $70 \%$ of the concussions occurred during games, and that head to head contact was the most frequent mechanism of injury, followed by head to ground and head to other body parts (foot, knee, elbow). Furthermore, they found that none of the concussions resulted from intentional heading of the ball. ${ }^{19}$

However, as acute injuries occur in a split second, it may be difficult for players or team medical staff to provide exact information on their mechanisms. A different approach is needed to describe the circumstances leading to head injuries more precisely. Video analysis has been used to study the mechanisms of concussive injury in elite national Australian rules football, ${ }^{29}{ }^{30}$ but this approach has not been used in association football. Therefore, the aim of the present study was to describe the mechanisms of head injuries and incidents with a high risk of head injury in elite football using video analysis.

\section{METHODS}

Videotapes and injury information were collected prospectively from the Norwegian professional football league during the 2000 season (April-October) and from the elite division in Iceland during the 1999 and 2000 seasons (MaySeptember).

The Norwegian Broadcasting Corporation (NRK) and TV2 Norway secured a weekly delivery of DVC pro or Beta SP quality video tapes from the Norwegian professional football league, and Beta SP quality video tapes were also made available by the Sports Department of the Icelandic National Broadcasting Service (Television) from the Icelandic league. National or regional television production teams with $1-3$ 
cameras were responsible for all recordings in Iceland and most of the recordings in Norway, although 20 matches from Norway were live broadcasts covered with six cameras.

Video recordings from 313 matches of 409 regular league or cup matches (77\%), 174/182 (league matches only) in Norway (96\%) and 139/227 (61\%) in Iceland were available from the television companies. Of these matches, 296 were covered in full, whereas in 17 matches the tapes covered 73 minutes on average (range 36 to 87 ). This corresponds to a total of 464.5 match hours, or 10219 player hours.

The tapes were reviewed to identify incidents where the player appeared to be hit in the head, the match was interrupted by the referee, and one or more players were lying down on the pitch for more than $15 \mathrm{~s}$. In addition, the player(s) had to appear to be in pain or receive medical treatment. $^{31}$ The incidents, including the entire playing sequence leading up to each of them, were transferred to a master videotape for further analysis. Each recording was edited to include three sequences: the entire playing situation including the play leading up to the injury at normal speed, one repetition of the injury, and a slow motion close up repeat of the injury.

The medical staff of each club collected the injury information on all acute injuries that occurred during the season. An injury was recorded if the player was unable to participate in training or match play for at least 1 day following the incident. Concussion was defined according to the clinical practice in Norway and Iceland-that is, a concussive injury was registered when a player either suffered loss of consciousness or had post-concussive amnesia for the incident. The incidence of injury was expressed as the number of injuries per 1000 player hours. Injuries were classified as minor when the player could not practice football normally or play matches for 1-7 days, moderate if absent for 8-21 days, and serious if absent for $>21$ days. $^{32} 33$ All players with an A squad contract were covered by the injury registration. A standardised injury questionnaire was used and reports were collected on a monthly basis. The form included information on the date of injury, as well as the approximate time during the match that the injury occurred. The injury location was registered and injuries classified as contusions, sprains, strains, fractures, or lacerations. Finally, each injury received a specific diagnosis using Orchard codes. ${ }^{34}$

Each incident identified on the videotapes was crossreferenced with the reports of head injuries from the team medical staff, and the original tapes were re-examined to find any head injuries that had not been identified in the first video review. The master videotape with all of the head incidents was analysed independently by three of us (TEA, $\mathrm{LE}$, and RB), who are experienced specialists in sports medicine. Disagreements were discussed in a consensus meeting, where the video recordings were re-evaluated and a final decision was made.

A specific questionnaire was developed to describe the injury mechanism and the events leading up to the head injury. The variables used in the questionnaire were defined as follows: $(a)$ the number of players involved in the incident (one, two, or three or more); $(b)$ if more than one player was involved, were they team mates, opponents, or both; $(c)$ type of playing action: heading duel, hit by the ball, kicked by opponent or team mate, running duel, tackling duel, positioning/forechecking, goalkeeping, or other; (d) what object hit the head: head, elbow, arm/hand, foot, knee, ball, shoulder, ground, goalpost, or other; $(e)$ if the elbow or arm/ hand hit the head, was the elbow above, at, or under shoulder level; $(f)$ for elbow/arm/hand cases, was the arm use passive, active, or an intentional strike; $(g)$ if the foot hit the head, was it a high kick or had the injured player been bending down; $(h)$ the point of impact: face, forehead, side of the head, back of the head, or cervical spine; and (i) for head to head heading duels, the relative horizontal speed of the colliding players; very high (both players moved at maximum or near maximum speed), high (one of the players moved at maximum speed, the other player was jogging), moderate (both players were jogging or one near maximum, the other moving slowly or standing still), or low (one or both players were standing, or one jogging or standing still).

\section{Statistics}

Differences in rates between Norway and Iceland were assessed using a Poisson regression model with indicator for country as independent variable and number of injuries or incidents as dependent variable. Differences in proportion of point of impact between two body parts were tested by $\chi^{2}$ test without any adjustments for multiple comparisons.

\section{RESULTS}

\section{Incidents and injuries}

During the 313 matches available on video (174 from the Norwegian professional league and 139 from the Icelandic elite division), 192 head incidents were recorded (124 from Norway and 68 from Iceland), a total of 18.8 per 1000 player hours (22.0 per 1000 player hours in Norway and 14.8 in Iceland, $p=0.009)$. Of the 297 acute time loss injuries reported, 17 (6\%) were head injuries ( 11 from Norway and six from Iceland; non-significant), which corresponds to an incidence of 1.7 per 1000 player hours (2.0 per 1000 player hours in Norway and 1.3 in Iceland; non-significant). When comparing the ratios of the head injuries to head incidents between the two countries, Iceland had rates 2.15 times higher than Norway $(\mathrm{p}<0.0001)$.

Of the 17 head injuries reported, 16 were identified on the videotapes ( 10 from Norway and six from Iceland). Of the 16 head injuries identified on video, five were classified as concussions (0.5 per 1000 player hours), two as nasal fractures, two as mandibular fractures, four as lacerations to the head or the face, one as a contusion, and three as muscular strains to the neck. The one injury not identified on video was a muscular strain to the neck. One of the facial fractures and one of the lacerations also resulted in injuries to the teeth. Eleven injuries were classified as minor, two as moderate, and three as serious.

\section{Video analysis}

The video analysis revealed 192 incidents involving head contact. In these incidents the most common playing action 9112 cases; 58\%) was a heading duel (fig 1). The opponent body part that most often hit the injured player was the elbow (66 incidents; 34\%), and in addition 13 cases were

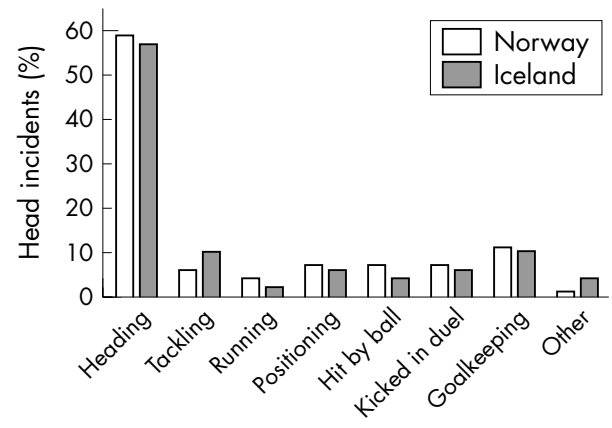

Figure 1 The primary mechanism causing trauma to the head in elite football in Norway ( $n=124$ incidents, white bars) and in Iceland ( $n=68$ incidents, grey bars). 


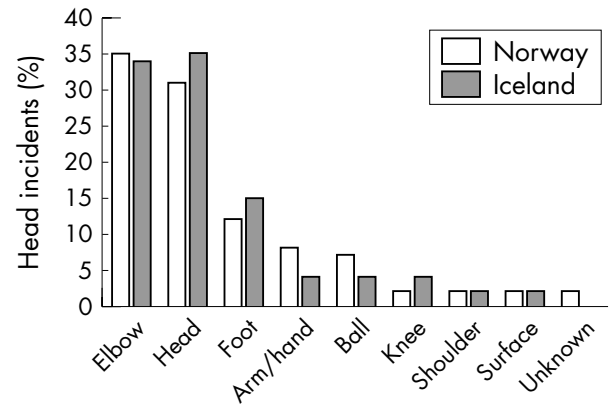

Figure 2 The opponent body part hitting the head of the exposed player in Norway ( $n=124$ incidents, white bars) and in Iceland ( $n=68$ incidents, grey bars).

caused by contact with the arm or hand (7\%) and four cases by the shoulder (2\%) (fig 2). In other words, a total of 83 cases $(43 \%)$ were caused by impact from the upper extremity. The point of impact on the head was the face in $57 \%$ of the cases, the back of the head in $22 \%$, the side of the head in $13 \%$, and the forehead in $6 \%$ (table 1 ). The point of impact was different between head and elbow incidents $(p<0.01)$. In addition, the point of impact was different between head incidents and the other modes (elbow, arm/hand, foot, and ball; all $\mathrm{p}<0.001$ ).

\section{Elbow, arm, or hand to head incidents}

In 79 of the incidents (five injuries) the primary mechanism was a blow from the elbow (66) or the arm/hand (13) to the head (fig 3). Of these, in 39 cases (49\%) the arm of the player causing the incident was above shoulder level and in 28 cases $(35 \%)$ it was at shoulder level. The use of the elbow was considered to be active in 61 of these incidents (77\%), and 16 incidents were assessed to be intentional strikes (20\%). The point of impact of the elbow or arm/hand on the head was the face $(73 \%)$ in 58 cases, the back of the head (15\%) in 12 , and the side of the head in 8 cases. Only one player was hit in the forehead.

In $53(67 \%)$ of these incidents the decision made by the referee was "no foul", while a free kick for the exposed player was awarded in 21 of the cases (fig 4). Of the free kicks awarded, four resulted in a yellow card and four in a red card. Of the five injuries occurring from blows by the elbow, arm, or hand, there was one concussion, one mandibular fracture, one facial laceration, and one neck muscle strain. Three of the injuries were minor, one was moderate, and one serious.

Table 1 The body part of the opponent hitting the exposed player versus the point of impact on the head ( $n=192$ head incidents and 16 injuries)

\begin{tabular}{|c|c|c|c|c|c|c|}
\hline \multirow[b]{2}{*}{$\begin{array}{l}\text { Body } \\
\text { part }\end{array}$} & \multicolumn{6}{|c|}{ Part of the head hit } \\
\hline & Face & $\begin{array}{l}\text { Back } \\
\text { of the } \\
\text { head }\end{array}$ & $\begin{array}{l}\text { Side } \\
\text { of the } \\
\text { head }\end{array}$ & Forehead & Unknown & Total \\
\hline Head & $19(-)$ & $22(3)$ & $15(1)$ & $6(1)$ & $-(-)$ & $62(5)$ \\
\hline Shoulder & $3(-)$ & $-(-)$ & $1(-)$ & $-(-)$ & $-(-)$ & $4(-)$ \\
\hline Elbow & 49 (3) & $10(-)$ & $6(-)$ & $1(-)$ & $-(-)$ & 66 (3) \\
\hline Arm/hand & $9(2)$ & $2(-)$ & $2(-)$ & $-(-)$ & $-(-)$ & $13(2)$ \\
\hline Knee & $3(1)$ & $1(-)$ & $1(-)$ & $-(-)$ & $-(-)$ & 5 (1) \\
\hline Foot & $17(3)$ & $4(-)$ & $-(-)$ & $4(-)$ & $-(-)$ & $25(3)$ \\
\hline Ball & $9(-)$ & 1 (1) & $-(-)$ & $1(-)$ & $-(-)$ & 11 (1) \\
\hline Surface & $-(-)$ & $2(-)$ & $-(-1)$ & $-(-)$ & $1(-)$ & $3(-)$ \\
\hline Unknown & $-(-)$ & $-(-)$ & $-(-)$ & $-(-)$ & $3(1)$ & $3(1)$ \\
\hline Total & 109 (9) & $42(4)$ & $25(1)$ & $12(1)$ & $4(1)$ & $192(16)$ \\
\hline
\end{tabular}

\section{Head to head incidents}

In 62 of the incidents (five injuries) the primary mechanism was head to head contact (fig 5). The point of impact on the injured player was the back of the head in 22 of the cases $(35 \%)$, the face in $19(31 \%)$, the side of the head in $15(24 \%)$, and the forehead in $6(10 \%)$. The relative horizontal speed of the players in the 62 head to head incidents was low in 44 cases $(71 \%)$ and moderate in 16 cases $(26 \%)$. The relative speed was high in only two of the head to head incidents.

The decision made by the referee was "no foul" in 44 cases $(71 \%)$, and in 12 cases $(20 \%)$ a free kick for the exposed player was awarded. None of the free kicks resulted in a yellow or red card. Of the five injuries there was one concussion, two contusions, and two lacerations, all of them minor.

\section{Foot to head incidents}

In 25 of the incidents ( 3 injuries) the primary mechanism was a kick to the head (fig 6). A "high kick" was the cause in 10 cases $(40 \%)$, while the injured player had bent down in five incidents. The point of impact on the head was the face in 17 cases $(68 \%)$, the forehead in four, and the back of the head in four cases.

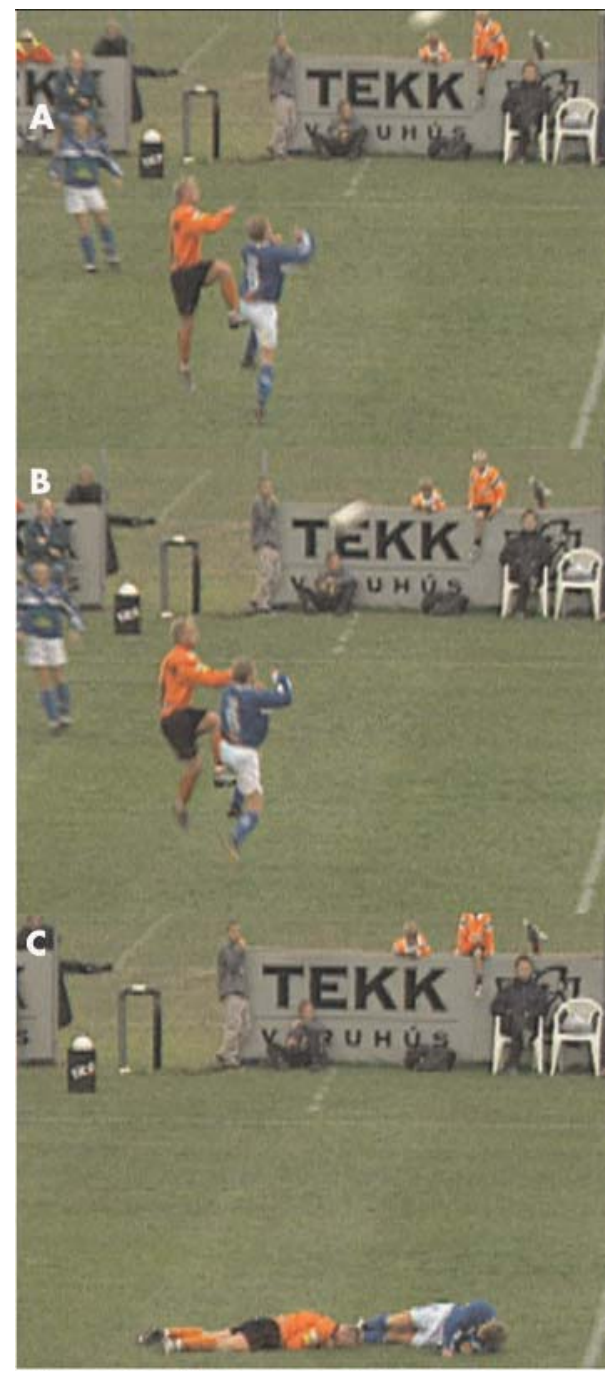

Figure 3 Elbow to head incident. (A) Close up just prior to impact. (B) Impact: the player in the orange shirt hits the opponent player on the side of the face with his elbow at shoulder level. (C) Both players down on the pitch just after the incident. 


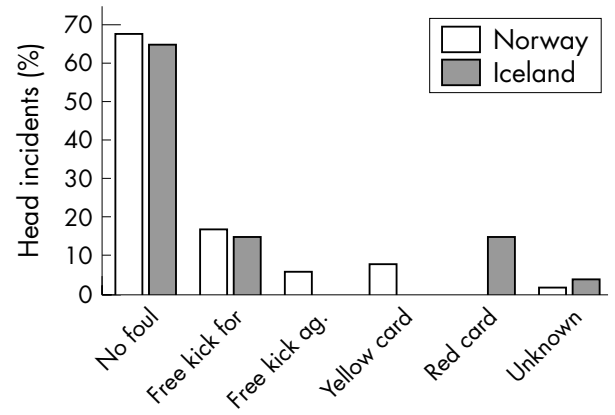

Figure 4 The referee's decision in incidents resulting from elbow, arm or hand to head contact in Norway $(n=53)$ and in Iceland $(n=26)$.

The referee's decision was "no foul" in 14 cases (56\%), while a free kick for the exposed player was awarded in eight. Of the free kicks awarded, two resulted in a yellow card and one in a red card. Three injuries occurred from foot to head incidents: one nasal fracture, one mandibular fracture, and one contusion. Two injuries were classified as moderate and one as serious.

\section{Goalkeeper incidents}

In $20(10 \%)$ of the incidents, the primary mechanism was involvement by the goalkeeper. Of these, the goalkeeper was the exposed player in nine cases, two of which resulted in an injury. The referee's decision was "no foul" in 15 (75\%) of the incidents and in five cases a free kick for the exposed player was awarded. None of the free kicks resulted in either a yellow or a red card. Two injuries occurred, one concussion and one mandibular fracture; both were classified as serious.

\section{DISCUSSION}

The aim of this study was to analyse the mechanisms of head injuries in Norwegian and Icelandic elite football based on video tapes of match incidents. The main findings were that $58 \%$ of the incidents resulted from heading duels, and that $41 \%$ of the cases were impacts from the arm, elbow, or hand, while 33\% were head to head impacts. Moreover, in the majority of the elbow incidents, the arm was at or above shoulder level and considered to be used actively or intentional in nearly all cases. Despite this, fouls were called in only one third of the cases.

\section{Methodological considerations}

When interpreting the results of the present study, some limitations must be borne in mind. Firstly, the diagnosis and grading of brain injury was based on reports by the team medical personnel. Under Scandinavian medical practice, diagnosis of brain injury is reserved for cases where a player suffers from loss of consciousness or retrograde amnesia. Diagnosing brain injury has always been a challenge for clinicians and to date there is no universal agreement on the standard definition or nature of concussion..$^{35}{ }^{36}$ However, recently the first steps towards guidelines for the diagnosis and management of the athletes who suffer concussive injuries have been taken. ${ }^{37}$ According to these guidelines, concussion may be caused either by a direct blow to the head or by a blow elsewhere on the body with an 'impulsive' force transmitted to the head, resulting in an immediate and short lived functional disturbance of neurological function and a graded set of clinical syndromes that may or may not involve loss of consciousness. This means that some of the facial fractures, lacerations, and even contusions to the neck in this study may also have lead to an unrecognised concussive injury. It is therefore reasonable to assume that concussive

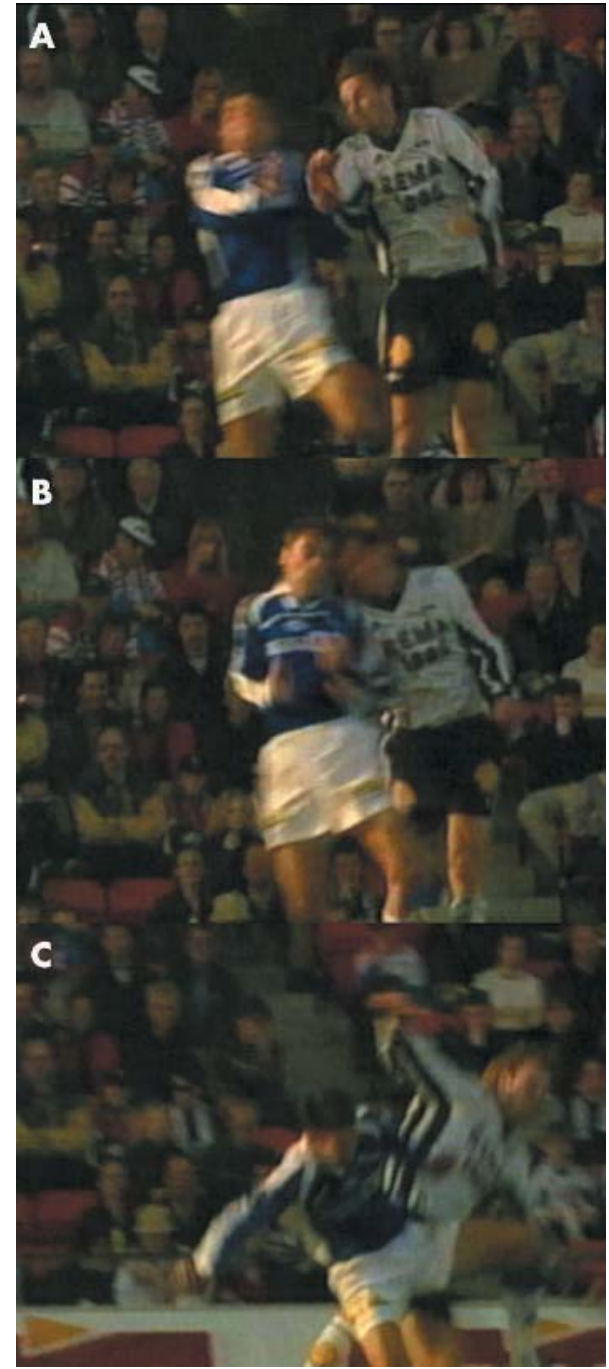

Figure 5 Head to head incident. (A) Close up just prior to impact. (B) Impact: the player in the white shirt hits the opponent on the side of the head with his forehead. (C) The moment just after impact.

injuries have been under-reported in the present study and that several more may be hidden among the head incidents that were not classified as time loss injuries. This can be verified from some of the video recordings where the player(s) appear to have sustained a mild brain injury, but an injury was not reported because the player either continued to play or practised as normal the following day. In a recent retrospective study by Delaney et al, ${ }^{20}$ only about one in five football players realised that they had suffered a concussion. Our incidence of concussions therefore represents a minimum estimate; the true incidence of mild brain injury with transient cognitive impairment may be several times higher.

Secondly, the assessment of the videos was subjective and qualitative, and in some cases based on tapes with less than optimal quality and a limited number of available camera views. Nevertheless, the number of head incidents was relatively large, and the analysis revealed distinct patterns and detailed information on the mechanisms for head injuries in football. Furthermore, all but one of the head injuries reported by the medical staff were identified on video. Even keeping these limitations in mind, a systematic analysis of injury situations from video would seem to be the obvious approach towards a more detailed understanding of 


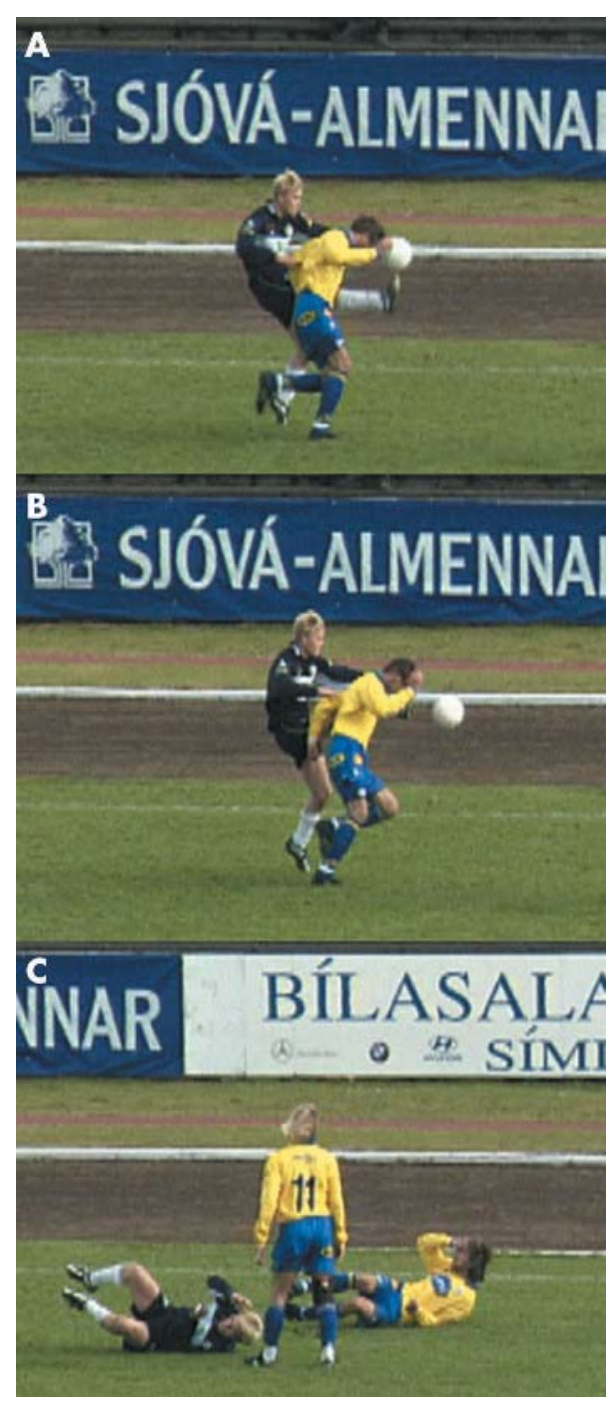

Figure 6 Foot to head incident. (A) Close up just prior to impact. (B) Impact: the player in dark blue tries to kick the ball with a high kick, while the opponent player attempts to head the ball and is hit in the face by the foot. (C) Both players down on the pitch just after impact.

the mechanisms for sports injuries, providing more reliable information than retrospective player interviews.

Finally, it should be noted that the video recordings used in this study were from matches only. Therefore, only mechanisms for head injuries and incidents in match play could be

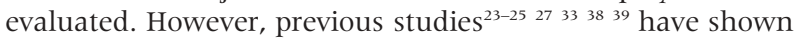
that most football injuries in elite players occur during match play, as was the case in the present study (data not shown). Whether the mechanisms for training and match injuries differ is unknown, although we would expect there to be fewer elbow to head and foot to head incidents and less foul play during training than in match play. In addition, there may be differences in injury mechanisms between elite male football players and other player populations (younger players, female players) that warrant attention in future studies.

\section{Injury mechanisms}

A number of studies show that selected groups of football players display some degree of cognitive dysfunction. ${ }^{5-11}$ However, whether the culprit is purposeful heading ${ }^{10}{ }^{11}$ or acute head injuries (including repeated, relatively mild concussions $)^{8}$ is not yet established. To further understand the relationship between heading, head injury, and cognitive deficits, it is important to learn more about head impacts during the football-that is, actual impacts of a ball on the head, exposure to heading at different competitive levels and age groups, and concussive injury rates. ${ }^{1}$ It is also necessary to conduct longitudinal studies focusing on exposure to heading, head injury, and cognition, as well as potential confounding factors such as alcohol and drug consumption and head injuries outside football. ${ }^{40}$ Furthermore, the specific mechanisms for head incidents and injuries in football need to be described in detail in order to establish targeted preventive measures.

The present video analysis clearly shows that the primary mechanism of head injury during matches in elite football is a contact mechanism between two opposing players occurring in a heading duel, rather than purposeful headings. In addition, the mechanism most often involves arm to head or head to head contact. This result contrasts somewhat with a prospective study on collegiate men and women, in which head to head contact dominated. ${ }^{19}$ Barnes et al ${ }^{41}$ and others ${ }^{42}$ described head to ground and head to goalpost as the main mechanisms for head injuries in football, whereas we found that these mechanisms are infrequent. Furthermore, situations where the players are hit in their head by the ball are also rare.

The present study showed a difference between the location and mode of impact. In head to head incidents, the location of impact was most commonly the side or the back of the head, whereas for elbow, arm, or hand to head incidents, foot to head incidents, and ball to head incidents, the face was the location most prone to impact. Moreover, impact to the forehead resulted in very few incidents regardless of the mode of impact. As discussed below, these findings are important when considering the potential of preventive headgear.

Elbow, arm, and hand contact to the head was the most common mechanism observed (fig 7). This is in contrast with findings from English professional football, showing that only in $1 \%$ of the match injuries was use of the elbow the injury mechanism. ${ }^{22}$ Furthermore, in most of the cases we observed, the elbow was used actively at or above shoulder level, possibly to fend off the opponent and get in position to head the ball. Additionally, even if relatively few in number, the foot to head incidents have the potential of causing severe injuries to the face and head. This study demonstrates that almost half of the foot to head incidents were "high kicks", where the point of impact was the face in the majority of the cases.

When comparing the results from Norway and Iceland, there are some differences in the frequency of head injuries and incidents. Fever head incidents occurred in Iceland, and the ratio of injuries to incidents was twice as high. We have no explanation for this. However, the detailed analyses of each incident and injury situation revealed no difference in the injury mechanisms between the two countries (see figs $1-3)$. This is significant, as it suggests that the results may be valid for club soccer more in general, and not just a result of a particular style of play in one country.

\section{Prevention of head injuries}

Head incidents accounted for $27 \%$ of the total number of incidents and $6 \%$ of the injuries in the present study. Next to tackling duels, heading duels cause most incidents and injuries in professional football, both in the defending and attacking playing phases. ${ }^{43}$ Although it should be acknowledged that this is in contrast to the figures from English professional football, which show that only $1 \%$ of the competition injuries occurred in heading duels, ${ }^{22}$ the present 


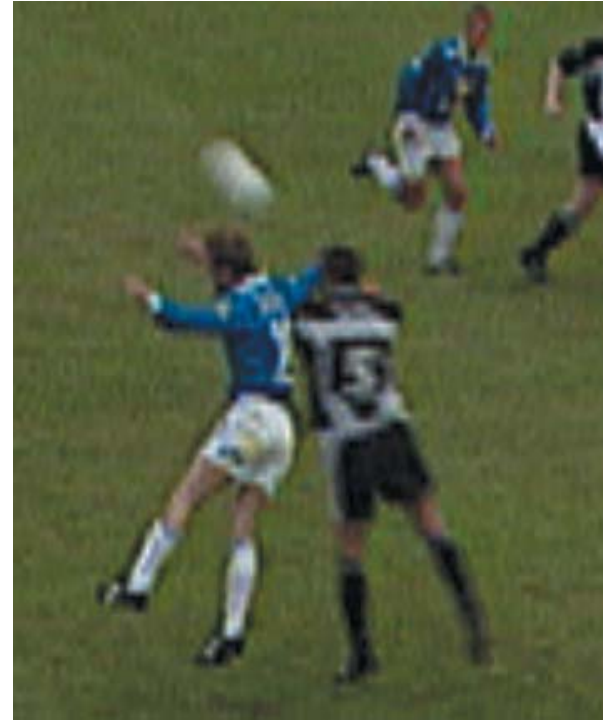

Figure 7 Typical injury mechanism. Elbow to head contact in a heading duel. The player in the blue shirt uses his right elbow actively above shoulder level to prevent the opponent player from reaching the ball.

data suggest that priority should be given to preventing head injuries.

In response to the concern that participation in football can lead to brain impairment, several manufacturers have developed headgear for football. Among North American youth football players, helmets and headbands have been used, but one experimental test of headbands showed little ability to attenuate the impact while heading a football ball. ${ }^{13}$ The present study shows that purposeful heading of the ball was not a cause of incidents and injuries. Moreover, in the majority of the cases, the point of impact was the face, and it is highly unlikely that headgear devices would be able to prevent these injuries.

Based on the current results, the most promising strategy to reduce head injury risk would appear to be discouraging elbow and arm use in heading duels. Although some of the elbow to head incidents led to free kicks, and a few of these even to a yellow or red card, in nearly $70 \%$ of these incidents the decision made by the referee was no foul. Our analysis also showed that $20 \%$ of the elbow to head incidents involved what appeared to be intentional strikes with the arm or elbow. Elbow use in football has been a focus among referees for some time, but this focus has mainly been directed at playing situations where the elbow or arm/hand is used intentionally and hence recognised to be a result of unfair playing. This may explain why so few of these cases were called as foul play.

Based on this, the obvious proposals to prevent head injuries are to ban the use of elbows at or above shoulder level in heading duels and to focus on stricter enforcement of the laws of the game in relation to elbow use when challenging for ball possession. This may possibly contribute to a reduction in the number of potentially dangerous elbow to head incidents in football. However, the game of football is highly competitive, and at the highest professional level, the glory and financial benefits of winning are considerable. It may therefore be tempting for players to make use of all means, including intentional fouls, to succeed. This development needs to be taken seriously and the approach to require the referees to be stricter in their implementation of the existing laws of the game may prove not to be sufficient. A 10 minute suspension for active "high elbowing" and "high kicking" (which may cause high impact serious injuries),

\section{WHAT IS ALREADY KNOWN ON THIS TOPIC}

- Purposeful heading is an important part of the game of football.

- Head injuries occur as a result of impact to the head or face and heading alone does not seem to cause brain injury.

- The main mechanisms for head injuries based on retrospective player interviews have previously been assumed to be head to head contact.

\section{WHAT THIS STUDY ADDS}

- A thorough video analysis reveals that heading duels are common in football and that many of these lead to situations with a high risk of injury.

- The two most frequent head incident mechanisms in elite football were elbow to head and head to head contact in heading duels.

- More than $40 \%$ of the head incidents are caused by impact by elbow, arm or hand.

- In the majority of the elbow to head incidents, the elbow was used actively or intentionally at or above shoulder level.

- Although the arm was used actively in $77 \%$ of these cases, no foul was usually called.

- Stricter enforcement of the rules of the game or rule changes concerning elbow use may be considered to reduce the risk of head injury in football.

similar to the existing rules of some other sports such as ice hockey and team handball, may be an improvement of the football rules that could possibly contribute to reduce aggressiveness in matches.

\section{CONCLUSIONS}

This study shows that video analysis can be used to provide detailed information about the mechanisms for head injuries in football. The two most frequent injury mechanisms were elbow to head and head to head contacts in heading duels. In the majority of the elbow to head incidents, the elbow was used actively or intentionally at or above shoulder level. The face is the main point of impact in head incidents in elite and professional football. Stricter rule enforcement or even changes in the laws of the game concerning elbow use may be considered to reduce the risk of head injury in football.

\section{Authors' affiliations}

T E Andersen, Á Árnason, L Engebretsen, R Bahr, Oslo Sports Trauma Research Center, Norwegian University of Sport and Physical Education, Oslo, Norway

Conflict of interest: none declared

\section{REFERENCES}

1 Kirkendall DT, Jordan SE, Garrett WE. Heading and head injuries in soccer. Sports Med 2001;31:369-86.

2 Tysvær AT, Storli OV, Bachen NI. Soccer injuries to the brain. A neurologic and electroencephalographic study of former players. Acta Neurol Scand 1989:80:151-6

3 Tysvær AT, Storli OV. Soccer injuries to the brain. A neurologic and electroencephalographic study of active football players. Am J Sports Med 1989;17:573-8. 
4 Sortland O, Tysvær AT. Brain damage in former association football players. An evaluation by cerebral computed tomography. Neuroradiology 1989;31:44-8

5 Tysvær AT, Löchen EA. Soccer injuries to the brain. A neuropsychologic study of former soccer players. Am J Sports Med 1991;19:56-60.

6 Gronwall D, Wrightson P. Cumulative effect of concussion. Lancet 1975;2:995-7.

7 Baroff GS. Is heading a soccer ball injurious to brain function? J Head Trauma Rehab 1998;13:45-52.

8 Matser JT, Kessels AG, Jordan BD. Chronic traumatic brain injury in professional soccer players. Neurology 1998;51:791-6.

9 Matser JT, Kessels AG, Lezak MD. Neuropsychological impairment in amateur soccer players. JAMA 1999;282:971-3.

10 Matser JT, Kessels AG, Lezak MD, et al. A dose-response relation of headers and concussions with cognitive impairment in professional soccer players. J Clin Exp Neuropsychol 2001;23:770-4.

11 Janda DH, Bir CA, Cheney AL. An evaluation of the cumulative concussive effect of soccer heading in the youth population. Inj Control Saf Promot 2002;9:25-31.

12 Naunheim RS, Bayly P, Standeven J, et al. Linear and angular head accelerations during heading of a soccer ball. Med Sci Sports Exerc 2003;35:1406-12.

13 Naunheim RS, Ryden A, Standeven J, et al. Does soccer headgear attenuate the impact when heading a soccer ball. Acad Emerg Med 2003;10:85-90.

14 Lohnes JH, Garrett WE, Monto RR. Soccer. In: Fu FH, Stone DA, eds. Sports injuries: mechanisms, prevention, treatment. Baltimore: Williams and Wilkins, 1994.

15 Sandelin J, Santavirta S, Kiviluoto O. Acute soccer injuries in Finland in 1980. Br J Sports Med 1985; 19:30-3.

16 Sullivan JA, Gross RH, Grana WA, et al. Evaluation of injuries in youth soccer. Am J Sports Med 1980;8:325-7.

17 Albert M. Descriptive three year data study of outdoor and indoor professional soccer injuries. Athletic Training 1983;18:218-20.

18 Powell JW, Barber-Foss KD. Traumatic brain injury in high school athletes. JAMA 1999;282:958-63.

19 Boden BP, Kirkendall DT, Garrett WEJ. Concussion incidence in elite college soccer players. Am J Sports Med 1998;26:238-41.

20 Delaney JS, Lacroix VJ, Leclerc $S$, et al. Concussion among university football and soccer players. Clin J Sport Med 2002;12:331-8.

21 Covassin T, Swanik CB, Sachs ML. Epidemiological considerations of concussions among intercollegiate athletes. Appl Neuropsychol 2003;10:12-20.

22 Hawkins RD, Hulse MA, Wilkinson C, et al. The association football medical research programme: an audit of injuries in professional football. $\mathrm{Br} J$ Sports Med 2001;35:43-7.

23 Nielsen $A B, Y$ de J. Epidemiology and traumatology of injuries in soccer. Am J Sports Med 1989;17:803-7.
24 Árnason Á, Gudmundsson A, Dahl HA, et al. Soccer injuries in Iceland. Scand J Med Sci Sports 1996;6:40-5

25 Lüthje $\mathbf{P}$, Nurmi I, Kataja $M$, et al. Epidemiology and traumatology of injuries in elite soccer: a prospective study in Finland. Scand J Med Sci Sports 1996:6:180-5.

26 Hawkins RD, Fuller CW. Risk assessment in professional football: an examination of accidents and incidents in the 1994 World Cup finals. Br J Sports Med 1996;30:165-70.

27 Dvorak J, Junge A. Football injuries and physical symptoms. A review of the literature. Am J Sports Med 2000;28:S3-9.

28 Peterson L, Junge A, Chomiak J, et al. Incidence of football injuries and complaints in different age groups and skill-level groups. Am J Sports Med 2000;28:S51-7.

29 McCrory PR, Berkovic SF. Video analysis of acute motor and convulsive manifestations in sport-related concussion. Neurology 2000:1488-91.

30 McIntosh AS, McCrory, Comerford J. The dynamics of concussive head impacts in rugby and Australian rules football. Med Sci Sports Exerc 2000;32:1980-4.

31 Andersen TE, Larsen O, Tenga A, et al. Football incident analysis (FIA): A new video-based method to describe injury mechanisms in professional football. Br J Sports Med 2003;37:226-32.

32 Lewin G. The incidence of injury in an English professional soccer club during one competetive season. Physiotherapy 1989;75:601-5.

33 Inklaar H. Soccer injuries. I: Incidence and severity. Sports Med 1994; 18:55-73.

34 Orchard J. Orchard Sports Injury Classification System (OSICS). Sports Health 1993;11:39-41.

35 McCrory P. Were you knocked out? A team physician's approach to initial concussion management. Med Sci Sports Exerc 1997;29:S207-12.

36 Johnston KM, McCrory P, Mohtadi NG, et al. Evidence-based review of sportrelated concussion: Clinical science. Clin Sports Med 2001;11:150-9.

37 Aubry M, Cantu R, Dvorak J, et al. Summary and agreement statement of the First International Conference on Concussion in Sport, Vienna 2001. Br J Sports Med 2002;36:6-10.

38 Hawkins RD, Fuller CW. A prospective epidemiological study of injuries in four English professional football clubs. Br J Sports Med 1999;33:196-203

39 Ekstrand J, Tropp H. The incidence of ankle sprains in soccer. Foot Ankle 1990;11:41-4.

40 Barnett C, Curran V. Dementia in footballers. Int J Geriatr Psychiatry 2003;18:88-9.

41 Barnes BC, Cooper L, Kirkendall DT. Concussion history in elite male and female soccer players. Am J Sports Med 1998;26:433-8.

42 Kelly JP, Rosenberg JH. Diagnosis and management of concussion in sports. Neurology 1997;48:575-80

43 Andersen TE, Tenga A, Engebretsen L, et al. Video analysis of injuries and incidents in Norwegian professional football. Br J Sports Med 2004;38:626-31 